\title{
Acolhimento no período de estágio curricular supervisionado em Educação Física
}

\author{
Host in the period supervised curriculum internship in Physical Education \\ Acogimiento en el período de práctica curricular supervisada en Educación Física
}

Recebido: 14/11/2021 | Revisado: 20/11/2021 | Aceito: 24/11/2021 | Publicado: 07/12/2021

\author{
Diane Mota Lima \\ ORCID: https://orcid.org/0000-0001-7933-2777 \\ Universidade Federal Rural do Rio de Janeiro, Brasil \\ E-mail: dianemotalima@gmail.com \\ Miguel Ataíde Pinto da Costa \\ ORCID: https://orcid.org/0000-0002-6498-3435 \\ Colégio Pedro II, Brasil \\ E-mail: miguelcosta.ef@gmail.com \\ José Henrique dos Santos \\ ORCID: https://orcid.org/0000-0002-2159-6611 \\ Universidade Federal Rural do Rio de Janeiro, Brasil \\ E-mail: henriquejoe@hotmail.com \\ Gabriela Simões \\ ORCID: https://orcid.org/0000-0003-1041-340X \\ Universidade Federal Rural do Rio de Janeiro, Brasil \\ E-mail: gabssimoes9@gmail.com \\ Rudson Procópio \\ ORCID: https://orcid.org/0000-0002-1578-2231 \\ Universidade Federal Rural do Rio de Janeiro, Brasil \\ E-mail: rudsonrj16@gmail.com \\ Elizangela Cely \\ ORCID: https://orcid.org/0000-0001-5905-9208 \\ Universidade Federal Rural do Rio de Janeiro, Brasil \\ E-mail: elizangela.cely@gmail.com \\ Célia Polati \\ ORCID: https://orcid.org/0000-0001-9047-184X \\ Universidade Federal Rural do Rio de Janeiro, Brasil \\ E-mail: celiapolati@gmail.com
}

\begin{abstract}
Resumo
Introdução: O Estágio Curricular Supervisionado (ECS) é um componente curricular dos cursos de licenciatura e período fundamental da formação inicial dos futuros professores. Dentre seus atores, destacam-se o estagiário e o Professor Supervisor (PS). Objetivo: Analisar e descrever as situações observadas nas vivências e interações entre a PS e seu estagiário na escola, a partir de experiências vividas no ECS do Ensino Fundamental. Metodologia: Esse estudo é um recorte de dissertação de Mestrado em Educação Física. Adotou-se uma abordagem qualitativa de pesquisa, de caráter descritivo e utilizando o método observacional. Para a coleta de dados foi realizada a observação in loco com Notas de Campo, em uma escola da Rede Pública de Ensino do Município de Seropédica/Rio de Janeiro. A amostra foi composta por uma PS e seu estagiário. Resultados: A relação firmada entre a PS e o estagiário foi marcada pela cooperação, interação, troca e colaboração, evidenciando características de um acolhimento realizado pela PS. Contudo, observou-se que as estratégias adotadas pela PS aconteciam de maneira intuitiva, possivelmente face a falta de orientação e conhecimento acerca de suas atribuições. Considerações finais: Ressalta-se a importância de uma formação específica, fundamentada e contextualizada do PS, a fim de subsidiar as ações supervisivas na escola. Ainda, alerta-se para a necessidade de maior parceria entre universidade-escola.
\end{abstract}

Palavras-chave: Estágio curricular supervisionado; Educação física escolar; Formação docente; Professor supervisor.

\begin{abstract}
Introduction: The Supervised Curriculum Internship (SCI) is a curricular component of undergraduate courses and a fundamental period of initial training for future teachers. Among its actors, the intern and the Supervisor Teacher (ST) stand out. Objective: Analyze and describe the situations observed in the experiences and interactions between the ST and its intern at school, based on experiences in the Elementary School SCI. Methodology: This study is part of a Master's thesis in Physical Education. A qualitative research approach, with a descriptive character and using the observational method. For data collection, on-site observation was carried out with Field Notes, in a school in the Public Teaching Network in the Municipality of Seropédica/Rio de Janeiro. The sample consisted of a ST and her intern. Results: The relationship established between the ST and the intern was marked by cooperation, interaction,
\end{abstract}


exchange and collaboration, evidencing characteristics of a reception carried out by the ST. However, it was observed that the strategies adopted by the ST happened in an intuitive way, possibly due to the lack of guidance and knowledge about their attributions. Final considerations: The importance of specific, grounded and contextualized training for the ST is emphasized, in order to support supervisory actions at school. Still, the need for greater partnership between university and school is alerted.

Keywords: Supervised curriculum internship; School physical education; Teacher training; Supervisor teacher.

\section{Resumen}

Introducción: La Práctica Curricular Supervisada (PCS) es un componente curricular de los cursos de pregrado y un período fundamental de formación inicial para los futuros docentes. Entre sus actores destacan el estudiante y el Profesor Supervisor (PS). Objetivo: Analizar y describir las situaciones observadas en las experiencias e interacciones entre el PS y su pasante en la escuela, con base en experiencias en el PCS de la Escuela Primaria. Metodología: Este estudio forma parte de una disertación de maestría en Educación Física. Se adoptó un enfoque de investigación cualitativa, de carácter descriptivo y utilizando el método observacional. Para la recolección de datos, se realizó observación in situ con Notas de Campo, en una escuela de la Red Pública de Enseñanza de en la ciudad de Seropédica/Rio de Janeiro. La muestra estuvo formada por una PS y su estudiante. Resultados: La relación que se estableció entre el PS y el estudiante estuvo marcada por la cooperación, interacción, intercambio y colaboración, evidenciando características de una recepción realizada por la PS. Sin embargo, se observó que las estrategias adoptadas por la PS sucedieron de manera intuitiva, posiblemente por la falta de orientación y conocimiento sobre sus atribuciones. Consideraciones finales: Se enfatiza la importancia de la formación específica, fundamentada y contextualizada para la PS, con el fin de apoyar las acciones de supervisión en la escuela. Aún así, se alerta sobre la necesidad de una mayor asociación entre la universidad y la escuela.

Palabras clave: Práctica curricular supervisada; Educación física escolar; Formación de profesores; Profesor supervisor.

\section{Introdução}

Por muito tempo o Estágio Curricular Supervisionado (ECS) era entendido como uma etapa apenas prática dos cursos de licenciatura, capaz de propiciar a aquisição de conhecimentos técnicos relativos à formação de professores, sobretudo relacionados à imitação de modelos. Nesse contexto, não havia preocupação com a reflexão crítica dos estagiários, pelo contrário, este era visto como um observador passivo no ambiente escolar (Pimenta \& Lima, 2010).

Ao encontro disso, autores indicam que essa formação docente distanciada das demandas do ambiente escolar, apenas centrada em questões burocráticas, tendem a pouco contribuir na formação da identidade profissional docente (Leite, 1988; Piconez, 1991; Pimenta, 2012). Diferente disso, entende-se que a formação docente deve primar pelo desenvolvimento de habilidades, conceitos e valores sobre como aprender e sobre as particularidades da futura profissão, contribuindo na construção de saberes fazeres e de identidades docentes (Pimenta, 2012).

Por esse ângulo, o ECS é um componente curricular dos cursos de licenciatura e período fundamental da formação inicial dos futuros professores. Esse componente curricular visa antecipar as vivências e experiências dos licenciandos acerca da cultura escolar em que estão inseridos, revelando questões essenciais para a constituição dos saberes, identidades e das práticas indispensáveis ao exercício profissional (Pimenta \& Lima, 2009).

Em termos de legislação, em 2008 surge a Lei n 11.788, mais conhecida como Lei do Estágio que, apesar de apresentar uma visão generalista em âmbito profissional, destaca atores importantes para que esse momento indispensável aconteça: o Estagiário, estudante de um curso de licenciatura que visa o aprimoramento profissional, e o Supervisor, profissional responsável por orientar e supervisionar o estudante no ambiente de trabalho, neste caso, a escola (Brasil, 2008).

No ambiente escolar, o estagiário tem contato com a realidade da profissão escolhida, bem como a oportunidade de, agora na posição de um professor em formação, ressignificar conceitos advindos de sua socialização antecipatória (Dubar, 2005). Nesse ínterim, o supervisor - nesta pesquisa adotado o termo Professor Supervisor (PS), professor da Educação Básica, recebe realce dentre os envolvidos com a formação inicial, por ser a figura que acompanhará de perto o processo formativo do estagiário, assumindo a missão de acolhê-lo e orientá-lo acerca de questões referentes à cultura e seus enfrentamentos da rotina docente. 
Embora o PS cumpra esse importante papel na formação dos licenciandos, no cenário brasileiro o ECS possui suas fragilidades, no que diz respeito à conexão e diálogo entre as universidades e escolas e, sobretudo, a falta de clareza sobre as condutas e atribuições a serem adotadas pelo PS na supervisão e acolhimento dos licenciandos (Benites, et al., 2013; Cely, et al., 2020; Cely et al., 2021). Desse modo, acredita-se que o PS deva ter uma formação específica para desempenhar a tarefa de supervisão, visto que, muitas vezes, não se sente preparado para formar futuros professores (Benites, et al., 2012a; Lima, et al., 2021a, 2021b).

Benites, et al. (2012b), em seu itinerário de pesquisas e discussões acerca da temática do ECS, sobretudo acerca da função e atribuições do PS, sinalizam questões importantes de serem levantadas a respeito de quem é o PS, apontando que:

[...] antes de tudo ele é um professor. Alguém que foi forjado pela sua constituição, que agrega saberes, competência e experiências relacionadas a um universo profissional e pessoal. Este professor-colaborador é formado para ensinar alunos da educação básica e recebe estagiários em situação de estágio obrigatório nas escolas, mas não recebe uma formação específica para se tornar um formador de professores (p. 567).

Nessa pesquisa, adotou-se o conceito de supervisão proposto por Ribeiro (2000, p. 90), sendo pontuado pelo autor que "supervisionar comporta a ideia de interajuda, de monitoração, de encorajamento para cada qual dê o seu melhor nas situações problemáticas com que se depara". Isso significa que a supervisão, mediada pelo PS, deverá buscar o desenvolvimento pessoal e profissional do estagiário, de forma que estes utilizem seus conhecimentos previamente construídos e experimentados. Para isso, é preciso que o PS tenha competências específicas para acolher os estagiários na escola, oportunizando-os, de forma interativa e reflexiva, maior contato com sua futura atuação profissional (Correa-Molina \& Gervais, 2008).

Reforçando a importância desse acolhimento no ambiente escolar, o Parecer do Conselho Nacional de Educação/Conselho Pleno (CNE/CP) no 28/2001 apresenta a escola como "instituição acolhedora" e a universidade como "instituição formadora". Nesse sentido, entende-se que os atores presentes na escola são responsáveis pela recepção e acolhimento dos estagiários, mas vê-se grande responsabilidade do PS nesse sentido, acolhendo e orientando os futuros professores no cotidiano escolar (Brasil, 2001).

O conceito de acolhimento aqui adotado baseou-se em Araújo (2014). Em sua definição, a autora entende a relação entre PS e estagiário enquanto ação mais próxima, responsável e interessada. Isso, pois, ao atuar no ambiente escolar, é permitido que o estagiário participe e interfira em situações e decisões dentro e fora das aulas, não sendo enxergado, de forma alguma, como observador passivo (Araújo, 2014). Nesse processo, oportuniza-se ao estagiário maior atenção à sua formação inicial e ao PS a oportunidade de formação e reflexão acerca de sua prática pedagógica.

Considerando o que foi apresentado acima, objetivou-se analisar e descrever as situações observadas nas vivências e interações entre a PS e seu estagiário na escola, a partir de experiências vividas no ECS do Ensino Fundamental. No mais, essa pesquisa se justifica pela escassez de estudos que viabilizem a observação in loco no desenvolvimento do ECS, além de poder contribuir na reflexão acerca da docência no contexto escolar, relacionando teoria e prática, sob a perspectiva crítica da observação.

\section{Metodologia}

Essa pesquisa é fruto da dissertação de Mestrado em Educação Física da primeira autora, a qual teve como objetivo geral analisar o acolhimento a partir da prática do PS com seu estagiário no decorrer do período de ECS nas aulas de educação física escolar (Lima, 2020). Como recorte da dissertação, esse artigo envolveu a coleta de dados realizada na "Escola B", situada na Baixada Fluminense do Rio de Janeiro. A "Escola B" - escola pública participante - foi selecionada pelo seu 
destaque positivo no Município de Seropédica - Município da Baixada Fluminense investigado. A amostra foi composta por uma PS da Educação Básica da Rede Pública de Ensino e seu estagiário.

Adotou-se uma abordagem qualitativa de pesquisa (Godoy, 1995), de caráter descritivo e utilizando o método observacional (Gil, 2008). Buscando analisar as práticas durante o curso de ECS, a coleta e registro dos dados ocorreu também in loco, a partir da observação da interação entre PS e estagiário, bem como da realidade docente e das demandas cotidianas da escola investigada. Dessa forma, como instrumentos utilizou-se: as observações in loco - buscando presenciar a interação entre PS e estagiário, na escola, dentro ou fora de situações de aula; com notas de campo - registrando datas, horários e sequência de acontecimentos de cada dia de observação. Assim, com o intuito de nortear a coleta de dados, foi elaborado pelos pesquisadores um "Roteiro para as observações in loco (notas de campo)", composto por um campo de detalhamento acerca do dia observado (escola, data, hora, local em que a aula de Educação Física foi realizada) e 15 questões.

Os registros das notas de campo foram feitos sem análise da pesquisadora, de forma literal, incluindo, por exemplo, situações-problema ocorridas, falas importantes dos envolvidos e dinâmicas dentro e fora das aulas. Posterior à observação, com o intuito de aprofundar as reflexões acerca dos dados coletados, foram acrescentadas impressões e informações pela pesquisadora. Dialogando com a estratégia de coleta de dados adotada, Tura (2003, p. 191) elucida que a observação propicia o “[...] descortinar de novos direcionamentos, novas focalizações e acertos de rota” e Rockwell (2009) indica que as notas de campo devem ser transcritas logo após a observação e, ainda, que estas tendem a ficar mais robustas conforme os registros vão sendo coletados em campo.

Os participantes dessa pesquisa preencheram e assinaram o Termo de Consentimento Livre e Esclarecido (TCLE) e o responsável da escola participante preencheu e assinou a Carta de Anuência para Autorização da Pesquisa. A coleta de dados aconteceu no ano de 2019, durante dois meses na unidade escolar, tendo sido realizadas cinco visitas, todas em quintas-feiras, de 12 às 17 horas, totalizando 25 horas de observação in loco. Cabe destacar que para que a coleta de dados acontecesse era necessária a presença da PS e de seu estagiário. Caso um não estivesse presente, a coleta de dados era desmarcada. Por isso, eram feitos contatos telefônicos prévios, verificando se nos dias agendados ambos estariam presentes.

Os dados registrados foram analisados e categorizados seguindo a Técnica de Análise de Conteúdo, realizada em três fases: pré-análise - divisão e organização dos dados coletados, seguida de uma leitura flutuante; exploração do material; e tratamento dos resultados - inferência, descrição e interpretação (Bardin, 1977).

\section{Resultados}

Para apresentação dos dados coletados na "escola B", optou-se por organizar essa seção em quatro subtítulos, a saber: "A escola", "A Professora Supervisora", "O estagiário" e, por fim, "O Estágio Curricular Supervisionado na Escola B", apresentados a seguir.

\subsection{A Escola}

A escola B, localizada no Município de Seropédica, Município da Baixada Fluminense do Rio de Janeiro, pertence à rede básica pública de ensino, atendendo o segmento do Ensino Fundamental. É considerada uma escola modelo pela Secretaria Municipal de Ensino por sua estrutura física, sua baixa carência de professores, a grande adesão dos alunos e por sua grade de horários com diversas modalidades de ensino. Ainda, é conhecida no Município como uma das melhores escolas do ensino público municipal. Até pouco tempo existiam projetos que atendiam a comunidade local (modalidades de danças e lutas), porém o corte de verbas os extinguiu.

Durante a realização dessa pesquisa o prédio escolar ainda acolhia outra unidade escolar de Creche/Educação Infantil, composta por oito turmas, uma vez que o prédio original passava por obras de manutenção, sem qualquer previsão para o fim 
da reforma. Com isso, no espaço destinado à escola B funcionavam duas escolas, contendo secretarias, corpo docente e gestões distintas. A estrutura física dessa escola é considerada de grande porte pela prefeitura por atender desde a creche ao nono ano do Ensino Fundamental e, ainda, o Ensino de Jovens e Adultos (EJA), nos turnos matutino, vespertino e noturno.

A escola B atende uma região carente e mesmo localizada perto da via (estrada) principal de transporte da cidade, sua rua não contava com asfalto, o que dificultava o acesso da comunidade, a pé ou por veículos. Havia funcionários no portão e pelos corredores, o que não impediu, entretanto, os embates entre alunos e a direção da escola, observados pela pesquisadora. Em relação ao componente curricular Educação Física, a escola contava com vários(as) professores(as), porém foi acompanhada apenas as aulas da PS, na presença do estagiário, às quintas-feiras, no turno da tarde (12 às 17 horas).

A quadra apresentava cobertura com marcações no solo bem apagadas, bebedouro próximo e bom espaço para atividades desportivas. Porém, não havia arquibancada ou locais para audiência, o que limitava o espaço de transeuntes e outros alunos, causando acidentes como boladas e tropeços. Além disso, a quadra era dividida com outra professora, o que gerava um grande transtorno na organização das aulas, pois podiam se contar em média 40 alunos em cada metade da quadra, fazendo atividades distintas nos horários das aulas de Educação Física.

A quadra é também o pátio da escola e, por isso, era utilizada várias vezes ao dia para pequenos intervalos de merenda e filas para a recepção de todos os alunos da escola. A PS e o estagiário paravam as atividades constantemente para ceder espaço para essas outras demandas da escola, o que prejudicava o andamento das aulas, ainda mais com crianças de terceiro e quarto ano do Ensino Fundamental, que foram as turmas observadas.

Uma questão importante relatada pela PS é a escassez de material esportivo para as aulas de Educação Física. A PS relatou não ser desinteresse do diretor, mas a ausência de investimento público governamental. A sala de material é bem reduzida e dividida com a equipe de limpeza da escola, contendo apenas duas bolas (uma de handebol e outra de futebol, bastante desgastada), alguns colchonetes e poucos bambolês. Os cones pequenos e a escada de atividades foram comprados pela PS, segundo relato da mesma.

\subsection{A Professora Supervisora}

No momento da coleta de dados, a PS tinha 37 anos de idade e residia no bairro da Penha/Rio de Janeiro. Em função de sua carreira profissional, era licenciada há onze anos pelo Centro Universitário Augusto Motta (UNISUAM) e trabalhava há três anos na escola B, lecionando a disciplina de Educação Física, com matrícula efetiva de 16h.

A PS se disponibilizou em participar da pesquisa, sendo sempre solícita, desde os contatos telefônicos até os dias de visita à escola. Nos dias de coleta na escola, a PS esteve disposta em responder as indagações inerentes à pesquisa. No início das visitas da pesquisadora, a PS apresentou certo nervosismo e procurava dar satisfação do que tinha feito em suas aulas ou sobre algum problema com aluno. Para deixá-la mais à vontade o instrumento de gravação de áudio não foi utilizado. A PS aparentou ter ficado mais tranquila após essa medida e as próximas visitas ocorreram de forma mais natural e espontânea.

A PS apresentava um perfil calmo, respeitoso com todos e não utilizava do tom de voz elevado em suas aulas para obter o domínio de turma. O trato com os alunos e estagiário era muito bom, de forma simpática, agregadora e respeitosa. A PS apresentou-se um pouco desmotivada com a profissão devido aos problemas inerentes à ausência de investimento público que afetam, principalmente, as condições de uso da quadra e de oferta dos materiais esportivos pela escola.

Essas situações apontadas são destacadas pela PS como prejudiciais para aulas mais elaboradas e o cumprimento de um planejamento mais diversificado para os alunos. Por receber muitos alunos de origem social carente, o uniforme adequado para atividade física não era exigido com rigor pela PS, visto que muitos alunos não tinham condições de comprar tênis ou uma bermuda, por exemplo. Isso também prejudicava o desenvolvimento das aulas de Educação Física, pela utilização de calças jeans e pés descalços. A PS também destacou que todas essas problemáticas sociais e políticas que a escola enfrentava 
atrapalhavam o desenvolvimento do ECS na escola, pois o estagiário ficava limitado em propor atividades, face aos materiais que eram possíveis de serem utilizados naquela realidade escolar.

A PS atendia a todos os anos do Ensino Fundamental na escola B e possuía turmas com um quantitativo médio de 40 alunos. O estagiário parecia ser visto pela PS como um "apoio" para as demandas desgastantes do dia a dia escolar, delegandoo muitas tarefas e concedendo-lhe grande autonomia no decorrer das aulas.

\subsection{O Estagiário}

No momento da coleta de dados, o estagiário era aluno do curso de Licenciatura em Educação Física da Universidade Federal Rural do Rio de Janeiro (universidade pesquisada), do $5^{\circ}$ período, sendo essa a sua primeira experiência no ECS. Entretanto, o estagiário possuía experiência pregressa em escolinhas de futebol da cidade. Essa experiência foi muito importante para o desenvolvimento do ECS, visto que ampliou seu conhecimento sobre a função docente e domínio de turma. Mesmo com todas as problemáticas de espaço e material da escola B, o estagiário conseguia se articular com a PS e não aparentava nervosismo diante da impossibilidade de cumprir algum tópico do plano de aula.

O estagiário residia próximo à escola e conhecia a realidade social da instituição e da região. Isso lhe garantiu certa vantagem, pois ele escolheu a escola pela proximidade e já conhecia algumas dessas situações-problemas mencionadas anteriormente. Durante as aulas, o estagiário apresentou domínio de turma e muita tranquilidade ao lidar com os alunos. Ainda, o estagiário tinha o respeito dos alunos e da PS que, por sua vez, elogiava seu comportamento como docente diante das turmas.

O estagiário apresentou empatia e grande envolvimento com o ambiente escolar, com a equipe de gestão e com a PS, além de disposição para tirar dúvidas e solucionar problemas que porventura aparecessem. Igualmente a PS, o estagiário se colocou muito solícito em contribuir com a pesquisa. Este não apresentou qualquer nervosismo ou contrariedade nas visitas da pesquisadora, apesar de algumas ausências do estagiário, por motivos pessoais, terem diminuído o número de interações da pesquisadora com ele no ambiente escolar.

\subsection{O Estágio Curricular Supervisionado na Escola B}

As observações foram feitas na escola B, em momentos de práticas pedagógicas, com a devida autorização da gestão escolar, da PS e do estagiário. As observações começaram após o início do período de ECS, devido a questões burocráticas, porém esse momento de recepção foi relatado pelos participantes nas entrevistas e no relatório final - também analisados pela pesquisadora e apresentados em sua dissertação (Lima, 2020).

As turmas eram cheias, com quantitativo de, em média, 40 alunos. A quadra era dividida, no mesmo horário, com outra professora de Educação Física, devido à carência de espaço físico destinado as aulas da disciplina. Além dessa situação, as aulas eram interrompidas para horários de entrada, saída e intervalo (recreio) de outras turmas. Com isso, a quadra se transformava no pátio da escola, espaço para as crianças brincarem livremente e, depois, se organizarem em filas para entrada e saída do prédio da escola. Durante esse período, os alunos que estavam tendo aula de Educação Física permaneciam nos cantos da quadra, com suas atividades de aula paralisadas para minimizar o risco de acidentes entre os alunos de diferentes faixas etárias, o que prejudicava a dinâmica e evolução das aulas de Educação Física. Após o "esvaziamento" da quadra pelos outros alunos (entrada, saída ou intervalos), a PS e o estagiário tinham que estruturar o espaço (metade da quadra) com os materiais e recobrar a atenção dos alunos para a continuidade das aulas, o que por vezes levava ao desinteresse e perda de estímulo por muitos alunos.

Os materiais configuravam-se como uma problemática muito apontada pelos participantes desta pesquisa. A escassez de material esportivo era algo alarmante na escola B, mesmo a PS relatando que o diretor fazia o que podia para comprar materiais, mas nem sempre tinha verba disponibilizada pelo poder público para esse fim específico. Com isso, o material se 
resumia em poucas bolas, alguns cones pequenos e bambolês. A PS relatou que a escada de atividades que ela utilizou foi comprada por ela e que o estagiário, de forma voluntária, ficou de conseguir uma bola com guizo emprestada na universidade para tentarem fazer uma aula diferente para os alunos.

O material esportivo da escola era armazenado em um local que também era depósito dos funcionários da limpeza, o que não permitia muito espaço para organização. Em alguns momentos de observação na escola, a PS relatava que essa falta de materiais prejudicava a execução do planejamento anual proposto pelo Município, pois não conseguia realizar todas as atividades pretendidas. Acrescentou também que essa situação dos materiais prejudicou o estagiário, pois mesmo sendo importante ter conhecimento da realidade das escolas públicas do Município, não podia aprender a lecionar diversas atividades em consequência dessa limitação. O estagiário também relatou diversas vezes essa questão dos materiais como fator complicador para suas intervenções e atividades pedagógicas planejadas.

A PS, no início do período de estágio, ficou um pouco tensa e preocupada em justificar quase todas as suas ações pedagógicas à observadora. Porém, com muita conversa e explicação da observadora, a PS entendeu que poderia seguir o ritmo normal de suas aulas e aparentou ter ficado mais à vontade e tranquila. A PS não apresentou qualquer dificuldade ou impasse nos contatos telefônicos e mensagens para agendamentos prévios de visitas.

No início da pesquisa, a PS acreditava que as entrevistas e visitas eram estratégias de fiscalização e acompanhamento do estagiário pela universidade, visto que nunca antes tinha sido feito esse contato entre universidade e escola (relato da professora). Contudo, após as explicações feitas pela pesquisadora, a PS compreendeu que se tratava de uma pesquisa ampla de um grupo de pesquisa vinculado à universidade sobre a temática do ECS.

A PS e o estagiário estabeleceram uma relação de respeito mútuo, organização e pautada no diálogo para resolver os problemas com os alunos. Essa relação era de parceria entre os dois, visto que o estagiário exercia uma importante função nas aulas Educação Física: "ajudar". O estagiário aparentava estar muito à vontade com o espaço escolar e com a PS, além de ter sido bem recebido pelos funcionários e alunos. A recepção do estagiário foi realizada de forma educada e respeitosa, visto que a presença do estagiário era algo muito esperado por todos.

Devido às problemáticas enfrentadas pela PS para ministrar suas aulas, o estagiário concedia grande ajuda e suporte para conseguir administrar o espaço, os materiais e o controle das turmas. A chegada do estagiário ocorria em momentos em que a aula já havia iniciado ( $1^{a}$ turma), sendo este muito aguardado pela PS e pelos alunos, sendo inclusive dito pela PS que algumas atividades só seriam possíveis na presença de seu estagiário.

Além disso, a PS atendia a diversas faixas etárias, o que exigia um planejamento e atenção diferenciada aos alunos nos momentos de "intervalo", para que não acontecessem acidentes ou dispersão. Nesses momentos, a PS solicitava bastante a ajuda do estagiário, como apoio no controle dos alunos e dos materiais.

O planejamento era conversado entre PS e estagiário em momentos fora da escola, por trocas de mensagens (relato dos participantes) e, rapidamente, antes das aulas para alinharem os objetivos e os materiais que seriam utilizados. O estagiário ajudava nessa divisão de materiais e organização dos alunos na quadra para as atividades. A dinâmica das turmas para as aulas de Educação Física era organizada com a PS e o estagiário, que era o responsável por buscar as crianças da sala para quadra e vice-versa. A PS geralmente dividia a turma em filas de meninos e meninas e o estagiário ficava responsável pelo grupo dos meninos.

Durante as aulas, a PS permanecia no local e ficava atenta aos conflitos dos alunos, porém deixou o protagonismo das aulas muitas vezes para o estagiário. O estagiário era tratado por ela como um colega de profissão e o apresentou para as turmas como professor. Ambos dividiam a organização e o comando das atividades, ficando na maioria do tempo o estagiário com os meninos e a PS com as meninas nas atividades iniciais. Isso porque a PS, como estratégia de aula, dividia a turma em meninos e meninas e ministrava as atividades para as meninas, enquanto o estagiário ministrava para os meninos. Ao longo da 
aula o estagiário assumia o processo com mais autonomia e comandava outras atividades, porém sempre com a PS na quadra com a turma.

A PS apresentava muita confiança em seu estagiário e o aguardava em aula para iniciar algumas atividades específicas, principalmente aquelas relativas ao futebol com os meninos. Certa vez, a PS comentou aos alunos que o professor - forma que ela utilizava para apresentar o estagiário nas turmas - era treinador na Escolinha do Flamengo, o que trouxe muita animação e interesse dos meninos pela constante presença do estagiário, assim como também do futebol nas aulas.

A presença do estagiário era um suporte significativo para a PS durante suas aulas de Educação Física, principalmente com as faixas etárias menores, pois essas turmas demonstravam mais interesse em participar das aulas e demandavam mais atenção da PS. Com isso, a presença do estagiário era fundamental para conseguir realizar a organização dos materiais e a execução do planejamento das aulas, recorde-se, divididas entre meninos e meninas.

O estagiário a ajudava em todos os passos da aula, desde organizar os materiais em quadra, buscar e levar turmas, resolver conflitos, orientar atividades aos meninos e guardar os materiais no depósito. Mesmo sem muitas explicações dos motivos dessas ações ao estagiário, ele sempre a ajudava nas aulas e sabia da importância da sua presença para a PS. Nos casos de acidentes ou qualquer situação que a PS precisava se ausentar, uma comunicação oral entre eles era feita para que o estagiário assumisse a aula enquanto a PS não retornasse. Durante esses momentos de ausência, o estagiário não apresentou nervosismo ou insegurança ao prosseguir com as atividades.

Em um dia de observação, a escola estava organizada para semana de provas e a PS iria ser a supervisora de uma prova de História para uma turma de $9^{\circ}$ ano do ensino fundamental considerada indisciplinada. A turma estava agitada e falante no início da avaliação, mesmo a PS, ainda sozinha, pedindo silêncio com educação para todos. Com a chegada do estagiário, a PS o orientou a supervisionar metade da sala, enquanto ela supervisionaria a outra metade, dividindo igualmente a tarefa de orientar os alunos. Os alunos demonstraram respeito pelo estagiário e a avaliação transcorreu sem maiores incidentes. Nesse dia, o estagiário foi liberado pela PS mais cedo, pois as atividades escolares já tinham sido finalizadas após as provas bimestrais.

A PS não tinha o hábito de fazer qualquer orientação ou sugestão de ação ao estagiário em momento de aula. Ambos relataram que devido a rotina concorrida de aulas e atenção aos alunos, muitas orientações de feedback eram realizadas pelo WhatsApp antes e depois das aulas. Durante os momentos de observação, foram presenciados convites ao estagiário para participar de um evento escolar e do Conselho de Classe. O estagiário demonstrou interesse em participar e não houve qualquer empecilho da coordenação ou da direção sobre sua participação.

Era percebido pela pesquisadora que a PS se preocupava com a formação do estagiário e em fornecer conhecimentos para que ele aprendesse a dinâmica de uma escola, mas que devido a sua realidade, sua atenção estava para todas as demandas que tinha que dar conta nas aulas, ou seja, a execução do planejamento e controle de turma eram o foco principal da aula e do estágio. Quando perguntada sobre a construção de conhecimento docente para o estagiário, a PS relatou que o fato de o estagiário estar ali presenciando todas as adversidades e a auxiliando com a disciplina das turmas, era um fator muito importante para aprendizagem do exercício do magistério.

A PS, mesmo sempre muito solícita ao estagiário, apresentava um comportamento inseguro na orientação do mesmo, exercendo sua atividade de supervisora quase que de forma "artesanal", ou seja, por instinto e a partir de tentativas que julgava serem as mais corretas, aparentemente, sem ter uma organização ou sistematização das etapas de orientação e supervisão de um estagiário. A PS apresentava interesse na formação do estagiário e no conhecimento sobre a sua importância no processo do estágio, mas não sabia "como proceder" para ser efetiva nessa formação, alegando muitas vezes falta de orientação e formação dela por parte da universidade. Além disso, não aparentava saber de sua "autoridade" perante os trâmites legais do ECS, como o cumprimento da carga horário mínima, frequência adequada na semana e intervenções práticas nas aulas que o 
estagiário deveria cumprir, o que muitas vezes ocasionava ausências ou atrasos do estagiário nas aulas, sem a devida comprovação adequada. Nesse sentido, sobre as orientações entre universidade-escola, a PS pontuou que: [...] gostaria que fosse harmoniosa, porque é importante, né? (PS).

Na maioria das vezes, a PS se comportava com gratidão ao estagiário, devido a toda ajuda prestada por ele nas aulas e não demonstrava estar à vontade para cobrar horários e frequência. Essa sensação de gratidão e de "não autoridade" foi percebida pela pesquisadora também na gestão da escola, que sempre se pronunciavam favoráveis em recepcionar os estagiários dessa universidade pesquisada, por precisarem muito de ajuda no desenvolvimento de projetos e andamento das aulas. Com isso, não foi constatada qualquer tipo de "fiscalização" ou "controle" no cumprimento dos dias e horários do estagiário e/ou organização de orientação ao estagiário.

\section{Discussão}

Tendo em vista a apresentação dos resultados, emergiram diferentes aspectos a partir das experiências vividas no ECS, na relação entre PS e estagiário, como: a receptividade; a atuação, preocupação e interesse da PS na formação do estagiário; a participação do estagiário no ambiente escolar; a relação entre PS e estagiário; e, a relação universidade-escola acerca das orientações de ECS, brevemente discutidas abaixo.

Em função da receptividade, o estagiário foi recebido, de forma agradável e respeitosa, inicialmente pela equipe gestora - que se preocupou inclusive com a sua disponibilidade de horários, deixando que o mesmo organizasse a grade de horários do estágio e, depois, pela PS - que buscou receber e incluir o estagiário em suas aulas e atividades cotidianas na escola. Esse momento de receptividade é fundamental para que o estagiário se sinta acolhido no ambiente escolar. A escola, por sua vez, enquanto "lócus formativo privilegiado" (Sarti, 2013, p. 218), não é um ambiente desconhecido para o estagiário, mas para muitos configura-se como o primeiro contato com a escola na posição de futuro professor. Por isso, todos os atores sociais presentes na escola serão parte do processo de construção desse futuro professor. Assim, a recepção do estagiário é uma fase essencial da integração inicial, caminhando rumo a um acolhimento com características formativas, isto é, voltadas à formação profissional do estagiário (Araújo, 2014).

Sobre a atuação, preocupação e interesse da PS na formação do estagiário, vê-se, pela observação, descrição e relatos, que a PS buscou apresentar ao estagiário a realidade escolar, os documentos Legais que norteavam o planejamento/prática pedagógica, as programações acerca dos eventos escolares, as condições físicas e estruturais para as aulas de Educação Física, a flexibilidade às demandas da rotina escolar, bem como buscou incluí-lo em tomadas de decisões, sugestões e adequações nas aulas. Araújo (2014) indica que quando o(a) PS apresenta ao estagiário os instrumentos de trabalho pedagógico como, por exemplo, o planejamento, este(a) estará contribuindo direta e positivamente para o processo de socialização profissional do futuro professor.

Em diálogo, para que aconteça o acolhimento formativo, é preciso que o estagiário conheça o ambiente escolar e o planejamento, assim como a identidade e comunidade desta escola, sendo possível, assim, propor intervenções pertinentes a essa realidade (Bueno \& Souza, 2012). Além disso, por se sentir parte do processo formativo do estagiário, a comunicação efetiva é uma das preocupações do(a) PS, buscando sanar dúvidas, questionamentos, bem como orientar e dar feedbacks. Nesse sentido, diferentes meios de comunicação podem ser viabilizados dentro e fora da escola, facilitando esses momentos de interação (Araújo, 2014). No caso dessa pesquisa, pode-se mencionar a estratégia de utilização do WhatsApp como meio para orientações pré e pós intervenções.

Em relação à participação do estagiário no ambiente escolar, percebeu-se que este estabeleceu boa relação com a PS e alunos(as). Face às condições para as aulas, sobretudo de recursos, a PS contava com a ajuda do estagiário em sua prática pedagógica que, consequentemente, oportunizava o contato com a realidade escolar atual em geral, isto é, metodologia nas 
aulas, vida docente e necessidades advindas da rotina profissional, importantes para a construção da identidade profissional. Assim, para que aconteça um acolhimento formativo, o PS deve incentivar e estimular os(as) estagiários(as) na carreira profissional escolhida, observando a realidade desse campo de atuação. Isso, pois, a falta de experiência junto às problemáticas enfrentadas pela escola podem ocasionar à insegurança e, consequentemente, ao desestímulo, tanto com o estágio quanto com a profissão (Araújo, 2014).

Nesse contexto, a socialização profissional - entendida como “[...] um processo de marcação e de incorporação dos indivíduos às práticas e rotinas institucionalizadas das equipes de trabalho" (Tardif \& Raymond, 2000, p. 217) - do estagiário caminharam rumo ao acolhimento formativo, pela possibilidade de ampliar trocas e diálogos acerca das experiências e demandas específicas do futuro local de atuação (Bueno \& Souza, 2012). Pois, foi permitido ao estagiário "experimentar o contato com a diversidade que caracteriza a docência" (Sarti, 2009, p. 137). Ademais, por meio das diferentes trocas, experiências e vivências, o estagiário poderá começar a refletir e construir sua própria identidade profissional (Dubar, 1997).

A relação entre PS e estagiário foi circundada por respeito, companheirismo e parceria. A PS não agia com superioridade, pelo contrário, buscava estabelecer uma relação de ajuda mútua. Embora não possuísse formação específica sobre como orientar estagiários, a PS buscava proporcionar vivências e experiências que julgava ser favoráveis para a formação de futuros professores. Essas características caminham e dialogam com um acolhimento formativo, pois neste modelo há a presença da parceria e cumplicidade, visando um ambiente de estágio com companheirismo entre PS e estagiário(a), de forma a facilitar a proximidade e relacionamento entre esses atores sociais. Isso, pois, o PS enxerga o(a) estagiário(a) como um futuro colega em formação ou, ainda, como um parceiro profissional, apresentando-o(a), inclusive, assim para os demais no ambiente escolar. Posturas como essa contribuem para o aumento da segurança e autonomia do estagiário no ambiente profissional (Araújo, 2014). Nessa perspectiva, indica-se que a função principal do(a) PS é aproximar o(a) estagiário(a) do ambiente de futura atuação, de forma a permitir a ampliação de conhecimentos oriundos da prática pedagógica (Correa-Molina \& Gervais, 2004).

E, por fim, ficou nítido que a relação universidade-escola acerca das orientações de ECS não aconteceu, sendo relatada essa ausência tanto pela PS quanto pelo estagiário. Os diálogos dos participantes da pesquisa vão ao encontro de uma das fragilidades do ECS no cenário brasileiro, isto é, a falta de conexão e diálogo entre universidades e escolas e, como consequência, a falta de clareza sobre as atribuições do(a) PS ao receber estagiários(as) na escola (Benites, et al., 2013; Cely, et al., 2020; Cely et al., 2021). Por isso, pesquisas como de Benites, et al. (2012a), Lima, et al. (2021a) e Lima, et al., (2021b) indicam a necessidade e importância da formação específica do(a) PS para desempenhar a tarefa de supervisão, pois muitas vezes estes(as) não se sentem preparados para formar futuros(as) professores(as).

\section{Considerações Finais}

A presente pesquisa, recorte de uma dissertação de mestrado, teve como objetivo analisar e descrever as situações observadas nas vivências e interações entre a PS e seu estagiário na escola, a partir de experiências vividas no ECS do Ensino Fundamental.

Em resposta ao objetivo traçado, depreendeu-se que, embora as problemáticas sóciopolíticas e organizacionais envolvidas na escola tenham, em certo grau, prejudicado o desenvolvimento do estágio, a relação firmada entre a PS e o estagiário foi marcada pela cooperação, interação, troca e colaboração, evidenciando características de um acolhimento realizado pela PS, isto é, um engajamento e interesse em colaborar com a formação do estagiário. Acredita-se que o protagonismo do licenciando possa ter contribuído. 
Em relação ao acolhimento, observou-se que as estratégias adotadas pela PS, para tornar o ambiente do estágio um momento formativo, estavam pautadas no que ela acreditava estar correto, ou seja, de maneira intuitiva, reforçando ainda mais a importância de uma formação específica, fundamentada e contextualizada, a fim de subsidiar as suas ações supervisivas.

Outra questão importante a ser destacada é que alguns depoimentos da PS corroboraram com a ideia de que na relação universidade-escola ainda existem lacunas que as distanciam. A falta de orientação e conhecimento perante os trâmites da universidade são fatores que podem dificultar o andamento dos estágios.

Ainda, sob um viés metodológico, a literatura científica apresenta inúmeras pesquisas a respeito do ECS e seu importante papel na formação de futuros professores, colaborando continuamente para o avanço da ciência. Em um movimento contrário, urge por investigações que se debruçam em estudos de campo focalizados na observação in loco no desenvolvimento dos estágios.

No mais, perspectiva-se que este estudo contribua com as discussões acerca do ECS e, sobretudo, as relações firmadas entre PS e estagiário no ambiente escolar, em que o primeiro reconheça o seu importante papel na formação inicial e que o segundo perceba que está em um ambiente de aprendizado, sendo fulcral estar aberto para tal.

\section{Referências}

Araújo, S. R. P. M. (2014). Acolhimento no estágio: entre modelos e possibilidades de formação docente. Dissertação (Mestrado em Educação) - Instituto de Biociências, Universidade Estadual Paulista, Rio Claro. https://repositorio.unesp.br/bitstream/handle/11449/127993/000850719.pdf?sequence=1

Bardin, L. (1977). Análise de conteúdo. Edições 70.

Benites, L. C., Souza Neto, S., Borges, C. \& Cyrino, M. (2012a). Qual o papel do professor colaborador no contexto do estágio curricular supervisionado na Educação Física? Revista Brasileira de Ciência e Movimento, Taguatinga, 20(4), 13-25. https://portalrevistas.ucb.br/index.php/RBCM/article/view/3286/2282

Benites, L. C., Cyrino, M. \& Souza Neto, S. (2012b). A prática de ensino como possibilidade de reflexão: concepções dos professores-colaboradores. In: Leite, Y. U. F., Marin, A. J., Pimenta, S. G. \& Reali, A. M. M. R. (Orgs.). Políticas de formação inicial e continuada de professores. Araraquara: Junqueira \& Marin Editores. 563-574.

Benites, L. C, Cyrino, M. \& Souza Neto, S. (2013). Estágio curricular supervisionado: a formação do professor-colaborador. Olh@ res, Guarulhos, 1(1), 116140. https://periodicos.unifesp.br/index.php/olhares/article/view/32

Brasil. (2001). Conselho Nacional de Educação. Parecer CNE/CP 9/2001. Diretrizes Curriculares Nacionais para a Formação de Professores da Educação Básica, em nível superior, curso de licenciatura, de graduação plena. Brasília, DF. http://portal.mec.gov.br/cne/arquivos/pdf/009.pdf

Brasil. (2008). Ministério da Educação. Lei Federal $n^{o}$. 11.788/ 2008. Dispõe sobre o estágio de estudantes. 1-10. http://portal.mec.gov.br/setec/arquivos/pdf/lei11788_25_09_08.pdf

Bueno, B. O. \& Souza, D. T. T. (2012). Pedagogia contemporânea e formação de professores em serviço: lógicas e dispositivos de um modelo em expansão. In: Bittar, M. Formação de professores. Edufscar.

Cely, E., Polati, C., Amaral, B. \& Silva, G. S. (2020). A (in)definição do papel do Professor Supervisor de estágio: realidades e perspectivas no contexto da Educação Física. In: Schütz, J. A. \& Mayer, L. Educação, História e Sociedade. Editora Ilustração.

Cely, E., Simões, G., Polati, C., Procópio, R., Mota, D. \& Henrique, J. (2021). Um olhar no espelho: percepções de uma professora supervisora de Estágio Curricular Supervisionado em Educação Física. Research, Society and Development, 10(13), e387101321305. http://dx.doi.org/10.33448/rsd-v10i13.21305

Correa-Molina, E. \& Gervais, C. (2008). Les stages en formation à l'enseignement: pratiques et perspectives théoriques. Quebec: Presse de 1'Université du Québec.

Dubar, C. (1997). A socialização: construção das identidades sociais e profissionais. Porto Editora LTDA.

Dubar, C. (2005). A socialização: Construção das identidades sociais e profissionais. Martins Fontes.

Gil, A. C. (2008). Métodos e técnicas de pesquisa social. (6a ed.), Atlas.

Godoy, A. S. (1995). Pesquisa qualitativa: tipos fundamentais. Revista de Administração de Empresas, 35(3), 20-29, https://www.scielo.br/pdf/rae/v35n3/ a04v35n3.pdf

Leite, Y. U. F. (1988). A formação de professores em nível de $2^{\circ}$ grau e a melhoria do ensino da escola pública. Tese (Doutorado) - Universidade Estadual de Campinas, Faculdade de Educação, Campinas, São Paulo. http://www.repositorio.unicamp.br/handle/REPOSIP/251913

Lima, D. M. (2020). Licenciandos de Educação Física no contato do Estágio Curricular Supervisionado: um estudo sobre indicadores de acolhimento. Dissertação (Mestrado em Educação Física) - Curso de Pós-graduação Mestrado Profissional em Rede de Educação Física (PROEF), Universidade Estadual 
Research, Society and Development, v. 10, n. 16, e75101623283, 2021

(CC BY 4.0) | ISSN 2525-3409 | DOI: http://dx.doi.org/10.33448/rsd-v10i16.23283

Paulista "Júlio Mesquita Filho", UNESP, Presidente Prudente. https://repositorio.unesp.br/bitstream/handle/11449/202205/mota_dl_me_pru d.pdf?sequen ce $=5 \&$ is Allowed $=\mathrm{y}$

Lima, D. M., Costa, M. A. P. \& Santos, J. H. (2021a). Indicadores importantes para formação de professores supervisores de Estágio Curricular Supervisionado. Revista Científica Multidisciplinar Núcleo do Conhecimento, 10, 20-29, jun. https://www.nucleodoconhecimento.com.br/educacao/curricularsupervisionado

Lima, D. M., Costa, M. A. P. \& Santos, J. H. (2021b). Licenciandos de Educação Básica no contexto do Estágio Curricular Supervisionado: um estudo sobre indicadores de acolhimento. Revista Internacional de Formação de Professores, Itapetininga, 6, e021015, 1-17, 2021b. https://periodicoscie ntificos.itp.ifsp. edu.br/index.php/rifp/article/view/457/225

Piconez, S. (1991). A prática de ensino e o estágio supervisionado. Papirus.

Pimenta, S. G. (2012). O estágio na formação de professores: unidade teoria e prática? (11a ed.), Cortez.

Pimenta, S. G. \& Lima, M. S. L. (2009). Estágio e Docência. (4a ed.), Cortez.

Pimenta, S. G. \& Lima, M. (2010). Estágio e docência. Cortez.

Ribeiro, D. (2000). A supervisão e o desenvolvimento da profissionalidade docente. In: Alarcão. I. (Org.). Escola reflexiva e supervisão: uma escola em desenvolvimento e aprendizagem. Porto Editora. p. 87-96.

Rockwell, E. (2009). La experiência etnográfica: historia y cultura en los procesos educativos. Paidós.

Sarti, F. M. (2009). Parceria intergeracional e formação docente. Educação em Revista, 25(2), 133-152, 2009.

Sarti, F. M. (2013). Pelos caminhos da Universitarização: reflexões a partir da masterização dos IUFM franceses. Educação em Revista, 29(4), $215-244$.

Tardif, M. \& Raymond, D. (2000). Saberes, tempo e aprendizagem do trabalho no magistério. Educação \& Sociedade, a. XXI, (73), $209-244$.

Tura, M. L. R. (2003). A observação do cotidiano escolar. In: Zago, N., Carvalho, M. P. \& Vilela, R. A. T. (Orgs.). Itinerários de pesquisa: perspectivas qualitativas em sociologia da educação. DP\&A. p. 183-206. 